\title{
Cerebral Blood Flow and Metabolism following Pancuronium Bromide in Newborn Lambs
}

\author{
JAQUES BELIK, L. CRAIG WAGERLE, AND MARIA DELIVORIA-PAPADOPOULOS \\ Departments of Physiology and Pediatrics, University of Pennsylvania School of Medicine, \\ Philadelphia, Pennsylvania 19104
}

\begin{abstract}
The purpose of this study was to evaluate cerebral blood flow and metabolism following pancuronium bromide paralysis in healthy newborn lambs. Cerebral blood flow and cerebral metabolic rate for $\mathrm{O}_{2}$ and glucose were measured along with blood pressure and blood gases before and again at 15 and $60 \mathrm{~min}$ following pancuronium paralysis in seven newborn lambs. Pancuronium bromide paralysis had no effect on any of these parameters either at 15 or $60 \mathrm{~min}$ of paralysis. Total cerebral blood flow, cerebral metabolic rate for $\mathrm{O}_{2}$, and cerebral metabolic rate for glucose were $87 \pm 6 \mathrm{ml} / \mathrm{min} / 100 \mathrm{~g}, 258 \pm 10 \mu \mathrm{mol} O_{2} /$ $\min / 100 \mathrm{~g}$, and $53 \pm 10 \mathrm{mmol}$ glucose $/ \mathrm{min} / 100 \mathrm{~g}$, respectively. Neither was any change in regional cerebral blood flow noted. In spite of being connected immediately to the ventilator, however, some animals experienced a transient increase (average $=32 \%$ ) in blood pressure, that was not associated with an increase in end tidal $\mathrm{CO}_{2}$. The data suggest that pancuronium paralysis in healthy awake newborn lambs does not lead to any alteration in cerebral blood flow or metabolism. (Pediatr Res 18:1305-1308, 1984)
\end{abstract}

\section{Abbreviations}

\section{CBF, cerebral blood flow}

$\mathrm{CMRO}_{2}$, cerebral metabolic rate for oxygen

$\mathrm{CMR}_{\text {glucose, }}$ cerebral metabolic rate for glucose

IVH, intraventricular hemorrhage

Neuromuscular blocking agents are used in infants in neonatal intensive care units to induce respiratory muscle paralysis. Among the nondepolarizing muscle relaxants, pancuronium bromide is the most commonly used agent, based on fewer side effects following its administration. A recent study, however, in preterm infants reported an increase in cerebral blood velocity measured by Doppler technique following paralysis with curare or pancuronium bromide (Pavulon) (9). Inasmuch as derangement of cerebral blood flow appears to be linked to the pathogenesis of intracranial hemorrhage encountered in the human premature brain (8), there is reason to postulate a relationship between cerebral blood flow changes following the use of skeletal muscle relaxants and intracranial hemorrhage in neonates.

While the effect of muscle relaxants upon the cerebrovascula-

Received January 2, 1983; accepted June 6, 1984.

Requests for reprints should be addressed to: Jaques Belik, M.D., c/o Maria Delivoria-Papadopoulos, M.D., Department of Pediatrics, Hospital of the University of Pennsylvania, 2nd Floor Maloney Building, 3400 Spruce Street, Philadelphia, PA 19104.

The research was supported by National Institutes of Health Grant RO1HD15973-01. These data were presented at the spring meetings of the Society for Pediatric Research in Washington, D. C., May 1983. ture of newborn animal models has not been studied, it has been shown in adult rats that there is an increase in cerebral blood flow and cerebral oxygen consumption following paralysis (1). The purpose of this study, therefore, was to evaluate the cerebral blood flow and metabolism following pancuronium bromide paralysis in healthy newborn lambs.

\section{MATERIALS AND METHODS}

Animal preparation. Studies were performed on newborn lambs less than $1 \mathrm{wk}$ of age. Two to 3 days prior to the experiment, ketamine $\mathrm{HCl}, 10 \mathrm{mg} / \mathrm{kg}$, was administered intramuscularly and additional 10-mg doses were given as necessary during the surgical procedure. Following subcutaneous infiltration with lidocaine $\mathrm{HCl}(1 \%)$, polyvinyl catheters (No. 5 French) were placed into the inferior vena cava for the administration of fluid and drugs, into the left brachial and femoral arteries for monitoring blood pressure and withdrawal of reference blood samples, and directly into the left cardiac ventricle through the femoral artery for injection of microspheres. Sagittal sinuses were chronically catheterized with a 22-gauge stainless steel cannula with an over-the-needle Teflon catheter.

Experimental protocol. On the day of the study, the animals were fed as usual. The larynx was visualized with the aid of a laryngoscope and an endotracheal tube was advanced and secured with tape to the mouth. The lambs were placed in a sling, padded, and wrapped for warmth and allowed to rest for approximately $1 \mathrm{~h}$ after all the catheters had been checked for patency. During this period, all animals became accustomed to the new environmental conditions and did not appear to be distressed by the endotracheal intubation. Following this period and after initial control measurements $(0 \mathrm{~min})$ were obtained, pancuronium bromide (Organon, W. Orange, $\mathrm{NJ} ; 1 \mathrm{mg} / \mathrm{ml}$ ), $0.1 \mathrm{mg} / \mathrm{kg}$, was infused into the inferior vena cava and the animal immediately was connected to a mechanical ventilator.

A slow intravenous infusion of pancuronium bromide, 0.1 $\mathrm{mg} / \mathrm{kg} / \mathrm{h}$, in normal saline $(10 \mathrm{ml} / \mathrm{h})$ was started following the initial bolus injection. Continuous monitoring of the end tidal $\mathrm{CO}_{2}$ allowed us to adjust the ventilator settings to maintain $\mathrm{PaCO}_{2}$ unchanged from the initial values. The fractional inspired oxygen concentration was adjusted to maintain the $\mathrm{PaO}_{2}$ constant. Animals were handled in accordance with the recommended actions for the Guiding Principles in the Care and Use of Animals, Department of Health, Education, and Welfare.

Arterial blood pressure, sagittal sinus pressure, and rectal temperature were continuously recorded on a Grass polygraph. End tidal $\mathrm{CO}_{2}$ was measured throughout the experiment. Arterial and sagittal sinus blood pressures were measured with Statham P23 Db pressure transducers. Rectal temperature was monitored with a model 43 TA telethermometer (Yellow Springs Instruments, Yellow Springs, $\mathrm{OH}$ ) and end tidal $\mathrm{CO}_{2}$ was measured by an 
infrared $\mathrm{CO}_{2}$ analyzer (LB2, Beckman Instruments, Fullerton, CA) sampling from the endotracheal tube.

Simultaneous arterial and sagittal sinus blood samples $(1.5 \mathrm{ml})$ were obtained together with each CBF measurement at control (0 min), $15 \mathrm{~min}$, and $60 \mathrm{~min}$ following pancuronium paralysis. Blood samples were analyzed in duplicate for $\mathrm{pH}, \mathrm{PaO}_{2}$, and $\mathrm{PaCO}_{2}$ by conventional electrodes (Radiometer, London Co., Cleveland, $\mathrm{OH}$ ). Oxygen content was determined with the use of a micro-oxygen content analyzer (Lex- $\mathrm{O}_{2}-\mathrm{Con}-\mathrm{K}$, Lexington Instruments Corp.). Serum glucose was measured in duplicate in a glucose analyzer (Beckman Instruments, Fullerton, CA). In addition, microhematocrits were obtained following each measurement in a standard microcentrifuge. $\mathrm{CMRO}_{2}$ and $\mathrm{CMR}_{\text {glucose }}$ were calculated as the product of cerebral blood flow and the respective arteriovenous difference for each substrate.

Measurement of cerebral blood flow. Blood flow to the brain was measured by injection of microspheres (5), $15-\mu \mathrm{m}$ diameter, into the left ventricle over a period of $15-30 \mathrm{~s}$. The microspheres were labeled with ${ }^{141} \mathrm{Ce},{ }^{85} \mathrm{Sr}$, and ${ }^{46} \mathrm{Sc}$ (3M Co., St. Paul, MN). Stock solutions of microspheres were sonicated for $5 \mathrm{~min}$ and shaken vigorously on a Vortex mixer for 2-4 min. Approximately 0.7 to 0.9 million microspheres were placed in specially prepared injection vials (5) and shaken on the Vortex mixer prior to injection. The vial containing the microspheres was attached to the left ventricular catheter and the contents injected by flushing $3-5 \mathrm{ml}$ of warmed saline solution through the vial. For $10 \mathrm{~s}$ prior to, during, and $60 \mathrm{~s}$ after the injection of microspheres, reference arterial blood samples were withdrawn from the left brachial artery into heparinized glass syringes.

At the end of each experiment, the animal was killed with an intravenous administration of euthanasia solution (T61, American Hoechst) and the brain was removed and sectioned into right and left cerebrum, cerebral gray matter, cerebral white matter, caudate nucleus, hippocampus, thalamus-hypothalamus, midbrain, cerebellum, pons, and medulla. Each brain region was weighed and placed into counting vials. The counting vials were filled with tissue to a height of less than $2.5 \mathrm{~cm}$ to minimize geometrical counting error. Reference blood samples were placed in glass counting vials and distilled water was added to lyse the red blood cells and allow the microspheres to settle to the bottom of the vial. Tissue and reference blood samples were counted for 5-10 min with a three-channel gamma counter (model 8000 , Beckman Instruments, Inc., Fullerton, CA). Energy windows were set at $125-170,460-550$, and $820-1060 \mathrm{keV}$ for ${ }^{141} \mathrm{Ce},{ }^{85} \mathrm{Sr}$, and ${ }^{46} \mathrm{Sc}$, respectively. Nuclide separation was performed using standard techniques (5). Blood flow to the brain and its regions was calculated with the formula: $\dot{Q}=A t \cdot \dot{Q} r / A r$ whereas $\dot{Q}$ is blood flow to tissue (ml/min), $A t$ and $A r$ are the activity (counts/ $\mathrm{min}$ ) in the tissue, and reference blood samples, respectively, and $\dot{Q} r$ is rate of withdrawal of the blood sample. Blood flow to each region was divided by its weight, multiplied by 100 and reported per $100 \mathrm{~g}$ of tissue. Cerebral vascular resistance was calculated as the ratio of mean arterial blood pressure to $\mathrm{CBF}$.

Statistical analysis. Statistical analysis was performed by oneway analysis of variance with repeated measurements. Differences between means were determined by paired $t$ test with Bonferoni correction when necessary. All differences were considered significant when $p<0.05$.

\section{RESULTS}

Seven animals were studied under this protocol. Paralysis was observed in all animals following intravenous administration of pancuronium bromide. The hematocrit, $\mathrm{pH}, \mathrm{PaCO}_{2}$, arterial, and sagittal sinus oxygen content are illustrated in Table 1. Pancuronium administration had no effect on any of these parameters and the hematocrit did not change during the whole experiment. During steady state measurements, heart rate and blood pressure did not change following paralysis. Heart rate was $217 \pm 17$ at control, $232 \pm 17$ at $15 \mathrm{~min}$, and $269 \pm 25$ beats $/ \mathrm{min}$ at $60 \mathrm{~min}$ $(p=\mathrm{NS})$. Blood pressure was $77 \pm 2$ at control,' $82 \pm 4$ at 15 min, and $79 \pm 5 \mathrm{~mm} \mathrm{Hg}$ at $60 \mathrm{~min}$. Following pancuronium administration and in spite of connecting the animal immediately to the ventilator, some animals experienced a transient increase in blood pressure as illustrated in Figure 1. This hypertensive state was not associated with an increase in end tidal $\mathrm{CO}_{2}$. The average transient increase in systolic blood pressure for the whole group was $32 \%$ following paralysis.

Figure 2 illustrates the cerebral blood flow and cerebrovascular resistance at control, $15 \mathrm{~min}$, and $60 \mathrm{~min}$ following paralysis. A significant change in either parameter was not seen following pancuronium bromide administration. Analysis of the regional blood flow revealed a blood flow of $83 \pm 6$ to the cerebrum, 103 \pm 9 to the midbrain, $92 \pm 7$ to the thalamus, $52 \pm 5$ to the hippocampus, $84 \pm 5$ to the caudate, $196 \pm 7$ to the cerebellum, $88 \pm 6$ to the pons, and $95 \pm 5 \mathrm{ml} / \mathrm{min} / 100 \mathrm{~g}$ to the medulla at 0 min. No significant changes in blood flow to any specific regions following paralysis were observed. The cerebral oxygen consumption following paralysis is depicted in Figure 3. Except for one animal that experienced an unexplained drop in oxygen consumption at $15 \mathrm{~min}$, the values were unchanged following pancuronium bromide paralysis. Arterial glucose concentration was $7.5 \pm 0.4 \mathrm{mmol} /$ liter at control, and was not statistically different at 15 and $60 \mathrm{~min}$ following paralysis. The $\mathrm{CMR}_{\text {glucose }}$ was $53 \pm 10$ at $0 \mathrm{~min}, 57 \pm 10$ at $15 \mathrm{~min}$, and $60 \pm 12 \mathrm{mmol} /$ $\mathrm{min} / 100 \mathrm{~g}$ at $60 \mathrm{~min}(p=\mathrm{NS})$. Sagittal sinus pressure was $5.4 \pm$ 0.6 at $0 \mathrm{~min}, 6.0 \pm 0.3$ at $15 \mathrm{~min}$, and $6.5 \pm 0.3 \mathrm{~mm} \mathrm{Hg}$ at 60 min following paralysis $(p=\mathrm{NS})$.

\section{DISCUSSION}

Contrary to what has been described in premature human neonates (9) and adult rats (1), cerebral blood flow in the newborn lamb does not increase following pancuronium bromide paralysis. Carlsson et al. (1) studied rats paralyzed with $d$-tubocurarine following catheter placement surgery and nitrous oxide anesthesia withdrawal. There was an increase in CBF and $\mathrm{CMRO}_{2}$ in the unanesthetized paralyzed group that could be blocked by propranolol priming or previous adrenalectomy. Immobilization stress with subsequent catecholamine release was postulated to be the mechanism to induce changes in cerebrovascular tone and metabolism. The present study design greatly differs from others inasmuch as this constitutes a chronic preparation where the animals did not experience any stress prior to paralysis. Although immobilization stress was proposed as the mechanism to induce changes in cerebral oxygen consumption and flow, it is conceivable that the observed changes were related to surgical stress and pain following anesthesia withdrawal. In

Table 1. Arterial blood gases following pancuronium bromide infusion in newborn lambs*

\begin{tabular}{cccccc}
\hline Time & $\begin{array}{c}\mathrm{HCT} \\
(\%)\end{array}$ & $\mathrm{pH}$ & $\begin{array}{c}\mathrm{PacO}_{2} \\
(\text { torr) }\end{array}$ & $\begin{array}{c}\text { Arterial } \\
\mathrm{O}_{2} \text { content } \\
(\mathrm{mM})\end{array}$ & $\begin{array}{c}\text { Sagittal sinus } \\
\mathrm{O}_{2} \text { content } \\
(\mathrm{mM})\end{array}$ \\
\hline Control $(0 \mathrm{~min})$ & $33 \pm 2$ & $7.45 \pm 0.01$ & $36.6 \pm 1.6$ & $6.3 \pm 0.4$ & $3.2 \pm 0.1$ \\
$15 \mathrm{~min}$ & $33 \pm 2$ & $7.42 \pm 0.01$ & $40.3 \pm 1.4$ & $6.5 \pm 0.4$ & $3.5 \pm 0.2$ \\
$60 \mathrm{~min}$ & $33 \pm 2$ & $7.44 \pm 0.01$ & $37.4 \pm 2.0$ & $6.3 \pm 0.4$ & $3.1 \pm 0.2$ \\
\hline
\end{tabular}

* Values are mean $\pm \mathrm{SE} . \mathrm{PaCO}_{2}$ at 0 min represents measurements taken immediately prior to infusion of pancuronium bromide. 

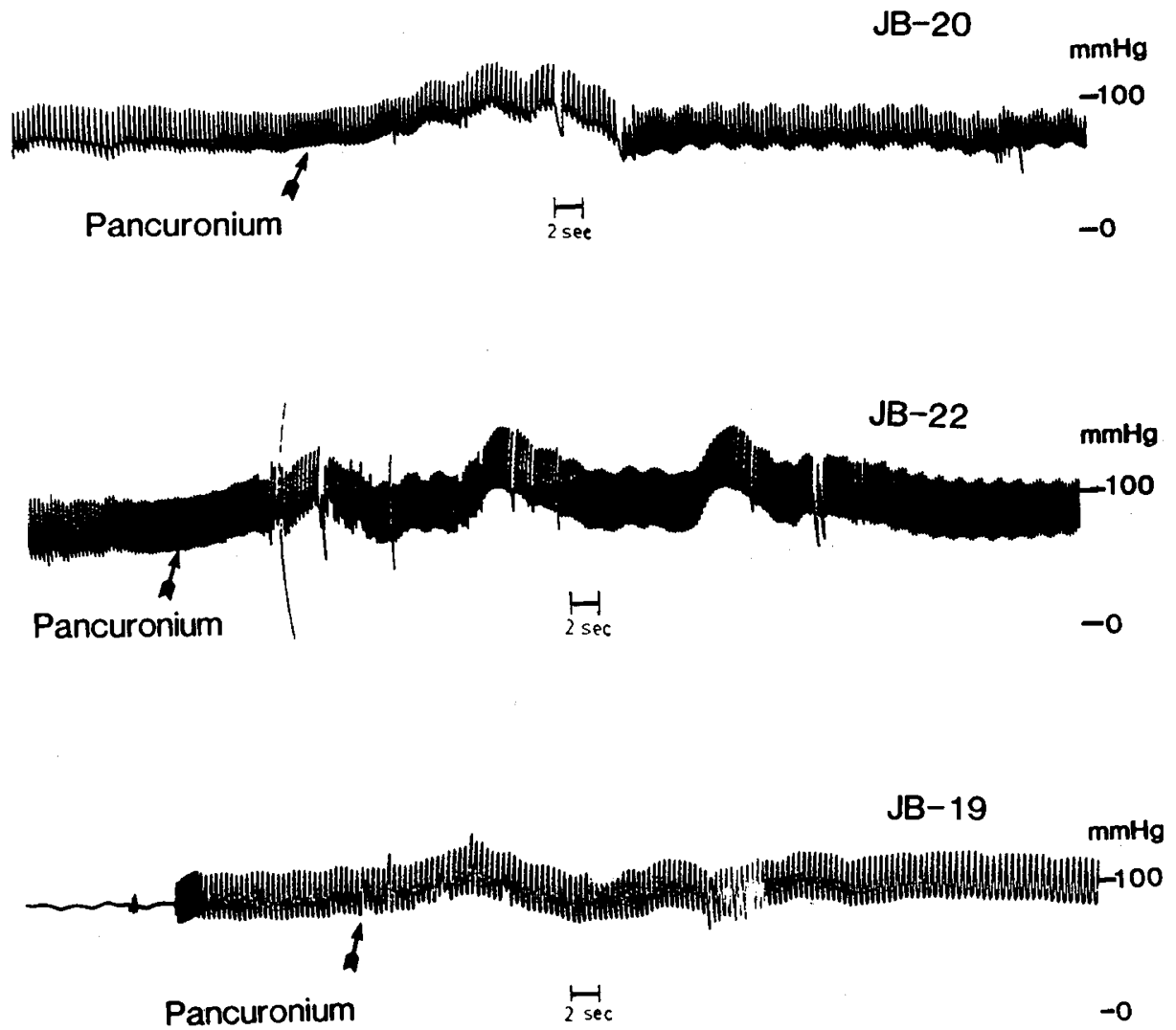

Fig. 1. Arterial blood pressure recordings from three lambs during bolus injection of $0.1 \mathrm{mg} / \mathrm{kg}$ pancuronium bromide into the inferior vena cava.
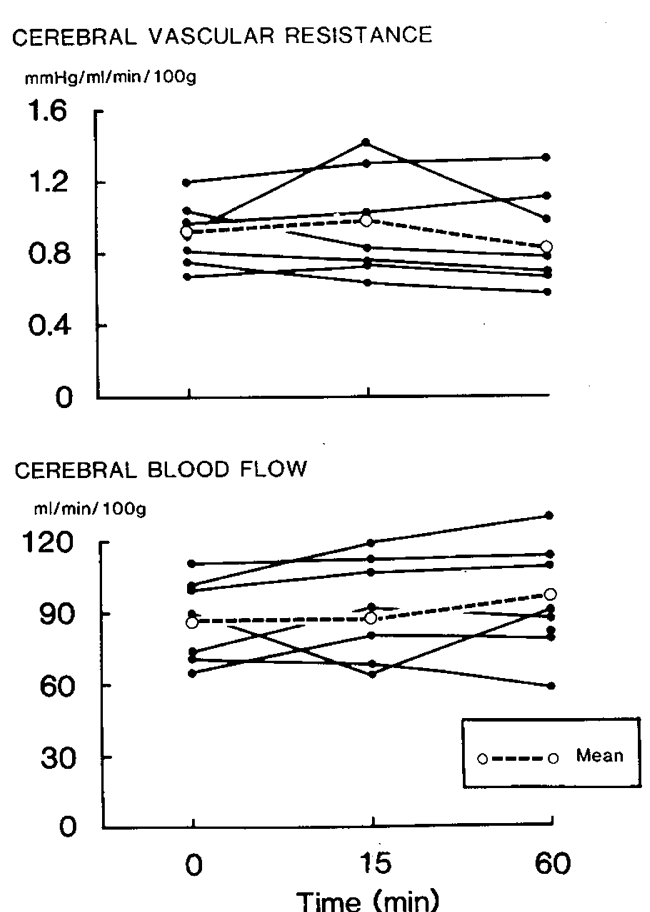

Fig. 2. Effect of pancuronium bromide paralysis on cerebral blood flow and cerebrovascular resistance in seven newborn lambs. Measurements at 0 min represent control values taken immediately prior to beginning infusion of pancuronium bromide.

the present study, we did not measure plasma catecholamine levels; however, sustained changes in heart rate and mean arterial blood pressure were not observed following pancuronium administration, making it unlikely that a significant catecholamine

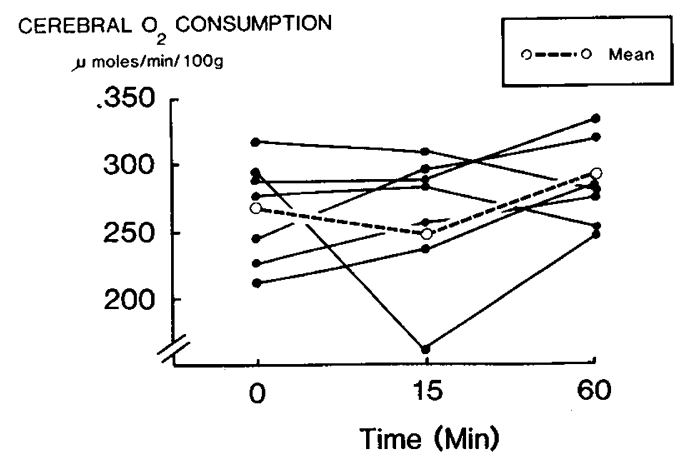

Fig. 3. Effect of pancuronium bromide paralysis on cerebral oxygen consumption in seven newborn lambs. Measurements at 0 min represent control values taken immediately prior to beginning infusion of pancuronium bromide.

surge had occurred in these animals. Therefore, the discrepant results, as compared to those of Carlsson et al., could be explained by the absence of stress reactions in the animals of the present study. It might also be postulated that either brain maturation makes the newborn less likely to manifest a response as compared to mature animals or that species differences may influence stress reactions to immobilization. In humans, administration of $d$ tubocurarine to a conscious adult did not lead to any changes in electroencephalogram, electrocardiogram, and blood pressure (13).

Apart from the effect of immobilization stress upon cerebral blood flow, one has to consider the possible direct effect of the muscle relaxant agents utilized. $d$-Tubocurarine is known to cause histamine release and sympathetic ganglion blockade (4). As opposed to these effects, pancuronium has been shown to induce adrenergic transmitter release from the postganglionic nerve endings (2). Furthermore, at least under thiamyal anesthe- 
sia, pancuronium induces a significant rise in free epinephrine concentration (17). Therefore, if the muscle relaxants were to be directly implicated in the pathogenesis of increased cerebral blood flow, one would expect a greater effect upon catecholamine release when pancuronium as opposed to $d$-tubocurarine is administered. Varma et al. (14), in anesthetized adult dogs, has shown a different physiologic response to these two muscle relaxants. In that study, cerebral blood flow was not determined, but a $63 \%$ increase in carotid blood flow followed $d$-tubocurarine administration while no change occurred in another group receiving pancuronium bromide.

In sick premature neonates, cerebral blood flow velocity, as determined by the Doppler technique, was noted to increase following paralysis with curare or pancuronium (9). Furthermore, intracranial pressure as measured by a transducer applied to the anterior fontanel increased significantly more upon elevation of peak inspiratory pressure and leg-raising as compared to values obtained prior to muscle relaxant administration (10). These observations were emphasized by the author as suggestive of a direct effect of muscle relaxants upon the cerebrovascular tone in the neonates with a loss of cerebral autoregulation. Unfortunately, blood gas results were not reported in the above study. A certain degree of hypoxia and hypercarbia are almost universally present when respiratory paralysis is clinically utilized and are well known factors associated with an increase in cerebral blood flow (16). Thus, the reported changes in these premature infants' cerebral blood velocity could have been directly related to changes in $\mathrm{PaCO}_{2}$ and $\mathrm{PaO}_{2}$ and not to loss of cerebral autoregulation. In fact, studies in newborn lambs under paralysis have shown that the CBF response to hypoxia is not different than the reported values for nonparalyzed awake animals, supporting an intact cerebral responsiveness to hypoxia (15).

Abrupt changes in arterial blood pressure have been associated with IVH in premature neonates. Transient increases in blood pressure state associated with hypercarbia have been documented to precede IVH in neonates with pneumothorax (6). The transient hypertension observed immediately following paralysis in our animals probably reflects a hypoxic phenomenon. Hypoxia following administration of muscle relaxants has been previously observed in neonates (11) and is probably related to the reported changes in diaphragmatic motion and alveolar ventilation leading to ventilation perfusion abnormalities $(3,12)$. Based on the response observed immediately following pancuronium administration, we speculate that the risk of hypoxia and perhaps hypercarbia following paralysis is the greatest in this initial period. Such abrupt changes in blood gases could lead to an increased incidence of IVH in premature neonates receiving muscle relaxants independent of any direct effect of the drugs upon the cerebral vascular tone.
These data suggest that pancuronium paralysis in healthy awake newborn lambs does not lead to any alteration in cerebral blood flow or metabolism contrary to what has been previously reported in other species. Following paralysis, however, a shortlasting increase in blood pressure is observed which may be associated with a transient ventilation perfusion mismatch. It is concluded that no direct effect of this drug upon cerebrovascular tone or metabolism could be appreciated in newborn lambs.

Acknowledgments. The authors wish to thank David W. Herbert and John H. Reynolds for technical assistance and Dorothy Zurlo for typing the manuscript.

\section{REFERENCES}

1. Carlsson C, Hagerdal M, Kaasick AE, Siesjo BK 1977 A catecholaminemedicated increase in cerebral oxygen uptake during immobilization stress in rats. Brain Res 199:223-231

2. Domenech JS, Garcia RC, Sasiain JMR, Loyola AO, Oroz JS 1976 Pancuronium bromide; an indirect sympathomimetic agent. Br J Anaesthiol 48:11431148

3. Froese AB, Bryan AC 1974 Effects of anesthesia and paralysis on diaphragmatic mechanics in man. Anesthesiology 41:242-255

4. Goodman LS, Gilman A 1975 The Pharmacological Basis of Therapeutics, 5 th ed. Macmillan Canada, Ltd, Toronto, p 575

5. Heymann MA, Payne BD, Hoffman JIE, Rudolph AM 1977 Blood flow measurements with radionuclide labeled particles. Prog Cardiovasc Dis 20:55-79

6. Hill A, Perlman JM, Volpe JJ 1982 Relationship of pneumothorax to the occurrence of intraventricular hemorrhage in the preterm newborn. Pediatrics 69:144-149

7. Jones MD Jr, Traytsman RJ, Simmons MA, Molteni RA 1981 Effects of changes in arterial $\mathrm{O}_{2}$ content on cerebral blood flow in the lamb. Am $J$ Physiol 240:H209-H215

8. Ment LR, Ehrenkranz RA, Lange RC, Rothstein PT, Duncan CC 1981 Alterations in cerebral blood flow in preterm infants with intraventricular hemorrhage. Pediatrics 68:763-769

9. Peabody JL 1981 Mechanical ventilation of the newborn: good news, bad news. Crit Care Med 9:710-713

10. Peabody JL 1981 Muscle relaxants-a potential danger to infants at risk for intraventricular hemorrhage. Pediatr Res 15:709

11. Philips JB, Setzer ES, Drummond WH, Nelson RM, Eitzer DV 1979 Hypoxemia in ventilated neonates after pancuronium paralysis. Lancet 1:877

12. Rehder K, Sessler AD, Rodarte JR 1977 Regional intrapulmonary gas distribution in awake and anesthetized-paralyzed man. J Appl Physiol 42:391

13. Smith SM, Brown HO, Toman JEP, Goodman LS 1947 The lack of cerebral effects of $d$-tubocurarine. Anesthesiology 8:1-14

14. Varma YS, Sharma PL, Minocha KB 1977 Comparative evaluation of cerebral and hepatic blood flow under $d$-tubocurarine and pancuronium in dogs. Indian J Med Res 66:317-322

15. Wagerle LC, Heffernan TM, Sacks LM, Delivoria-Papadopoulos M 1983 Sympathetic effect on cerebral blood flow regulation to hypoxic newborn lambs. Am J Physiol 245 (14, Heart Circ Physiol):H487-H494

16. Wigglesworth JS, Pape KE 1978 An integrated model for haemorrhagic and ischemic lesions in the newborn brain. Early Human Dev 2:179

17. Zsigmond EK, Matsuki A, Kothary SP, Kelsch RC, Vadnay L 1974 The effects of pancuronium bromide on plasma norepinephrine and cortisol concentration during thiamylal induction. Can Anaesthiol Soc J 21:145-152 